\title{
Retraction Note: Atom-vacancy hopping in ultra-high vacuum at room temperature in $\mathrm{SrTiO}_{3}(001)$
}

\author{
Rasheed Atif $^{1}$
}

Published online: 17 November 2021

(c) The Author(s), under exclusive licence to Springer-Verlag GmbH, DE part of Springer Nature 2021

\section{Retraction to: Applied Physics A (2021) 127:111 https://doi.org/10.1007/s00339- 020-04205-x}

The author has retracted this article because it contains data used without prior authorization, as required by their institution's protocols. The author apologizes for their misunderstanding of the institutional protocols, as well as the inconvenience caused by this oversight.

Author Rasheed Atif agrees to this retraction.

Publisher's Note Springer Nature remains neutral with regard to jurisdictional claims in published maps and institutional affiliations.

The original article can be found online at https://doi.org/10.1007/ s00339-020-04205-x.

Rasheed Atif

aatif.rasheed@materials.ox.ac.uk

1 Department of Materials, University of Oxford, Parks Road, Oxford OX1 3PH, UK 